\title{
AS POLÍTICAS DE PROTEÇÃO NO DESEMPREGO EM PORTUGAL
}

\author{
Pedro Adão e Silva \\ Instituto Universitário de Lisboa (ISCTE-IUL), CIES-IUL, Lisboa, Portugal \\ Mariana Trigo Pereira \\ Deloitte Consultores, S.A., Lisboa, Portugal
}

\section{Entre os insiders e os midsiders: a proteção no desemprego em Portugal}

Neste artigo, analisamos as políticas públicas de proteção do risco de desemprego em Portugal, procurando compreender quem são os desempregados protegidos e com que intensidade ocorre essa proteção, bem como o modo como estas duas dimensões evoluíram ao longo do tempo. ${ }^{1} \mathrm{O}$ artigo começa por descrever as alterações nas condições de acesso às prestações de desemprego para depois discutir, brevemente, a segmentação do mercado de trabalho português e a forma como esta condiciona o padrão de riscos. Na segunda parte do artigo são analisados os rácios de proteção no desemprego e a variação da despesa com o risco de desemprego no conjunto da despesa pública e com proteção social. O artigo conclui que em Portugal, considerando o regime de proteção existente, nas últimas décadas, os rácios de proteção têm sido elevados, o que sugere que em lugar de estarmos perante uma clivagem entre insiders e outsiders, é mais adequado falar de uma clivagem entre insiders e midsiders (indivíduos com alguma proteção, em muitos casos residual). Ainda assim, os mecanismos de proteção não só se têm revelado incapazes de se adaptar às transformações aceleradas que têm ocorrido no mercado de trabalho português - invertendo a tendência de rácios relativamente elevados de desempregados protegidos - como se assiste a uma diminuição significativa dos valores e duração das prestações, que não deixarão de gerar "armadilhas de pobreza" entre os desempregados.

\section{A proteção no desemprego em Portugal}

As raízes da proteção no desemprego para todos os trabalhadores, através de um seguro social unificado, podem ser encontradas no discurso imperial do chanceler Bismarck, proferido no Reichstag em 1872 (Kuhnle e Sander, 2010). Se é aí que

$1 \quad$ Alguns dos dados deste artigo foram apresentados na conferência, “1986-2010: a economia portuguesa na União Europeia", que se realizou nos dia 4 e 5 de julho de 2012. Agradecemos vários comentários feitos pela assistência. O António Dornelas, o José Luís Albuquerque e o Pedro Marques leram uma versão anterior deste texto e fizeram um conjunto de sugestões que nos foram muito úteis e que, naturalmente, agradecemos. 
radicam as origens dos modernos estados-providência, o debate sobre o tipo de instrumento mais eficaz para responder ao desemprego, designadamente dos trabalhadores da indústria, seria mais tarde, no início do século $\mathrm{XX}$, que se definiria com contornos duradouros o desenho das políticas de subsídio de desemprego. Deste ponto de vista, os debates ocorridos na Suécia e no Reino Unido seriam determinantes para a opção pelo seguro social, financiado através de cotizações dos empregadores e dos trabalhadores (Heclo, 1974). Apesar da oposição do movimento operário, que se opunha à obrigatoriedade das contribuições por conta dos trabalhadores, na maior parte dos países do capitalismo avançado, no período imediatamente anterior à Segunda Guerra Mundial, seria instituída uma prestação social para responder à eventualidade do desemprego (Pierson, 1998). Se bem que os princípios corporativos (Goodin e outros, 1999) ficassem plasmados na maioria das legislações nacionais, Portugal demoraria a instituir uma prestação deste tipo.

Como em muitas outras dimensões do nosso modelo de proteção social, os princípios típicos do modelo corporativo só seriam institucionalizados mais tarde face aos nossos parceiros europeus e também aos da Europa do Sul (Silva, 2002). Foi após a transição para a democracia que Portugal instituiu o direito ao subsídio de desemprego, alargando a proteção com a criação do subsídio social de desemprego em 1985 e, finalmente, preenchendo uma lacuna no edifício de proteção social, com a criação do direito a um rendimento mínimo em 1997, entretanto renomeado rendimento social de inserção (Silva, 1998, 2011; Capucha e outros, 2005).

Entretanto, em muitos países europeus, a última década foi palco de importantes reformas nos regimes de proteção no desemprego, num contexto de crescimento dos níveis de desemprego e de crescente segmentação dos mercados laborais. Referem-se como algumas destas tendências de evolução, uma maior ativação dos beneficiários, o reforço do princípio da autossuficiência e redução da dependência das prestações sociais; um recuo, nalguns casos, de benefícios universais assentes em direitos de cidadania, a favor de maior seletividade e dependência de certos benefícios sociais de vínculos estáveis com o mercado de trabalho (remercadorização); uma reorientação das políticas redistributivas beneficiando os trabalhadores de baixos rendimentos em desfavor dos agregados familiares de baixos recursos - targeting tendo em vista maior eficiência da despesa social; e ainda o reforço, em inúmeros países, das sanções decorrentes da rejeição de ofertas de trabalho por parte de beneficiários de prestações de desemprego. É com este pano de fundo que devem, também, ser interpretadas as transformações recentes ocorridas em Portugal.

O regime português de proteção no desemprego compreende, hoje, um conjunto de prestações monetárias - o subsídio de desemprego (SD) é uma prestação de montante proporcional aos rendimentos que antecedem o desemprego, com prazo de garantia, assente no princípio do seguro social, enquanto o subsídio social de desemprego (SSD) corresponde a uma prestação de montante fixo com prazo de garantia menos exigente que o SD e sujeita a condição de recursos. Para além do SSD inicial, é possível qualificar para um SSD subsequente, uma vez terminado o $\mathrm{SD}$, desde que verificada a condição de recursos. Finalmente o rendimento social de inserção (RSI), não apenas dirigido aos desempregados registados nos centros 
de emprego, é uma prestação monetária diferencial, sujeita a condição de recursos e ao cumprimento de um contrato de inserção (ver anexos, quadro 1).

Na próxima secção analisaremos as alterações nas regras de acesso à proteção no desemprego, tomando como referência as últimas duas décadas (ver anexos, figuras 1 e 2).

\section{Quem beneficia de proteção no desemprego?}

Os anos 90 assistiram a grande estabilidade nas condições de acesso aos subsídios de desemprego. Até então, a última reforma, de 1989, alargara significativamente a cobertura destes benefícios, definindo um prazo de garantia que se manteve constante até 2003 (ver anexos, figura 1). Em 1999 foi criado o "subsídio de desemprego parcial", o qual veio permitir a acumulação do subsídio com trabalho a tempo parcial, introduzindo maior flexibilidade na utilização desta prestação.

Em 2003 o Programa de Emprego e Proteção Social (PEPS), entre outras medidas de natureza temporária, facilitou o acesso ao subsídio de desemprego através de uma redução significativa do prazo de garantia. As alterações introduzidas pelo PEPS acabaram por permanecer em vigor até 2006, altura em que, no seguimento de um acordo entre o governo e os parceiros sociais, se restringiu novamente o acesso ao subsídio de desemprego - estabelecendo-se, no entanto, um prazo de garantia mais favorável do que aquele que vigorava antes de 2003.

Em resposta ao rápido crescimento dos níveis de desemprego que acompanhou o desenrolar da crise económica, em 2010 flexibilizou-se novamente o acesso ao subsídio de desemprego, pela redução temporária do prazo de garantia, bem como o acesso ao subsídio social de desemprego, através da elevação do limiar de rendimentos per capita que determina a elegibilidade dos beneficiários destas prestações (de 80 para $110 \%$ do IAS). ${ }^{2}$ Contudo, ainda em 2010, foi implementada a nova lei da condição de recursos que harmonizou as condições de acesso de um conjunto de prestações de natureza não contributiva, ou fracamente contributiva, como é o caso do SSD. Esta alteração resultou na aplicação de uma nova escala de equivalência, menos generosa, e da consideração de apoios em espécie, rendimentos financeiros e situação patrimonial na aferição do nível de recursos dos requerentes do subsídio social de desemprego, restringindo o acesso a esta prestação.

Depois do fim das medidas temporárias e da reposição das anteriores condições de acesso ao subsídio de desemprego em 2011, em 2012 é novamente facilitado o acesso a esta prestação, por redução do período mínimo de contribuições exigido, tal como previsto no programa de assistência financeira (Memorando de Entendimento sobre as Condicionalidades da Política Económica, versão de 11 de maio de 2011).

Se é verdade que as alterações nos instrumentos de política são relevantes para compreender os níveis de proteção no desemprego, as características e

2 IAS - indexante dos apoios sociais (Lei n. ํㅡㄴ-B/2006, de 29 de dezembro) é o referencial para a fixação das contribuições, pensões e outras prestações sociais $(419,22$ euros em 2012). 
transformações do mercado de trabalho desempenham um papel decisivo. Para além de o mercado de trabalho português apresentar um conjunto de singularidades no contexto europeu (taxas de emprego tradicionalmente muito elevadas, em particular para as mulheres, e um peso dos trabalhadores de baixos salários também elevado), tem sofrido transformações muito aceleradas, em particular na última década (Dornelas e outros, 2011). Partindo de níveis de desemprego baixos, designadamente quando comparado com os países do modelo corporativo e também da Europa do Sul, Portugal não só viu crescer o desemprego a um ritmo bem superior à média europeia, como esse crescimento acelerou a segmentação do sistema de emprego, nomeadamente por força do aumento do stock de desemprego jovem (ver anexos, figura 5).

Este crescimento do fluxo de desempregados, por si só, coloca uma enorme pressão sobre os mecanismos de proteção no desemprego. No entanto, o aumento diferenciado do desemprego tem também efeitos diretos nos níveis de proteção. Desde logo tendo em conta que a probabilidade de um jovem ter preenchido os prazos de garantia necessários para aceder ao SD são menores - o que, por si só, tende a fazer diminuir os rácios de proteção.

A segmentação do mercado de trabalho português não se prende apenas com o ritmo diferenciado de crescimento do desemprego. Tem, aliás, como característica mais marcante relações laborais fracas e instáveis, com elevados níveis de rotação, que provocam uma erosão significativa do capital humano e são um fator de quebra de produtividade. Se bem que os níveis de rigidez laboral, com a revisão do Código do Trabalho de 2008, já não sejam os mais elevados no contexto da OCDE (Venn, 2009), tendo inclusivamente continuado a decrescer nos últimos anos, a rigidez formal continua a coexistir com níveis elevados de flexibilidade de facto. Sinal disso é o forte crescimento, ao longo da última década e meia, dos contrato a prazo no total do emprego, bem como de outras formas atípicas de relação laboral, como a intensificação do recurso aos recibos verdes, em muitos casos não obedecendo, na prática, aos requisitos do trabalho independente. Mais uma vez, a utilização deste tipo de vínculos é diferenciada (Oliveira e Carvalho, 2010), incidindo em particular sobre os jovens (mais de 50\% têm empregos temporários). Esta tendência, aliás, tende a intensificar-se, considerando que os custos de ajustamento têm incidido essencialmente sobre os vínculos precários. Com efeito, $2 / 3$ dos trabalhadores que perderam emprego em 2010 tinham contrato a prazo, acrescendo o facto de o fluxo do desemprego para o emprego ser, hoje, quase exclusivamente regulado por contratos a prazo - 90\% em 2010, numa subida de quase 20\% apenas no espaço de uma década (Centeno e Novo, 2012).

A combinação de um mercado de trabalho muito segmentado com fluxos de e para o emprego assentes crescentemente em vínculos atípicos tem efeitos evidentes do lado da proteção no desemprego. Os dados relativos ao primeiro trimestre de 2012 revelam não apenas que $81 \%$ dos desempregados estão registados nos centros de emprego, como também que só $44 \%$ dos desempregados estão hoje protegidos - sendo esse valor maior se considerarmos os desempregados inscritos $(55 \%)$. Entre os protegidos, uma larga maioria beneficia de SD, enquanto cerca de $18 \%$ recebe SSD. Ainda que de modo apenas indiciário, é possível sustentar 
que a ausência de proteção recai essencialmente sobre: os jovens em início de carreira, que não cumprem o prazo de garantia; os trabalhadores com vínculos precários e elevada rotatividade (muitos deles jovens); e os desempregados de muito longa duração, que esgotaram o direito ao subsídio.

Já se olharmos para quem são os desempregados, considerando os inscritos e os beneficiários de prestações de desemprego por idade, podemos consolidar a asserção de que há uma subproteção relativa dos jovens. Da decomposição do conjunto dos desempregados é possível concluir que, enquanto no desemprego apurado pelo INE a proporção de jovens (15-24 anos de idade) era, em 2011, de $20,3 \%$, se considerarmos apenas o desemprego registado no IEFP este valor diminuía para cerca de metade $(11,5 \%)$, representando um peso ainda inferior $(5,7 \%)$ se considerarmos o total dos beneficiários de proteção no desemprego.

\section{A evolução da proteção no desemprego}

Se uma análise estática já nos oferece alguma leitura da assimetria de proteção no desemprego e permite saber quais são os grupos menos protegidos, uma análise diacrónica não apenas consolida esta leitura, como nos permite compreender o modo como os rácios de proteção evoluíram ao longo do tempo. Esta evolução depende não apenas de alterações ao nível da regras de acesso a estas prestações, como também de variações de "volume" decorrentes da própria dinâmica do mercado de trabalho - fluxo de desempregados, estrutura do emprego e configuração das relações laborais.

No início da década de 1990 os rácios de proteção no desemprego eram reduzidos - cerca de $30 \%$ (ver anexos, figura 8 ). Entretanto, esse valor subiu rapidamente, tendo alcançado um primeiro pico em 1993 (68,1\%), na sequência de um fluxo intenso de desemprego decorrente da recessão económica então ocorrida. Após um declínio dos rácios de proteção, esta tornar-se-ia mais abrangente no início da década de 2000, atingindo valores acima dos $80 \%$. Desde então, pese embora se tenha assistido a um declínio continuado dos rácios de proteção, estes coexistiram com uma recomposição da partição interna por tipo de proteção. Com a aprovação do PEPS, as exigências para se qualificar para esta prestação foram flexibilizadas e assistiu-se a uma subida do número de beneficiários, num contexto em que os recipientes do SSD diminuíam. As alterações das regras de acesso em 2006 fizeram com que o rácio de desempregados protegidos pelo SD continuasse a baixar, tendo sido compensado por um aumento dos beneficiários do SSD - ainda que esta prestação tenha passado a ter maiores exigências quanto à condição de recursos. Com alterações temporárias nas regras de acesso e com o desencadear da crise em 2008, a intensidade do fluxo de desempregados, combinada com um stock que entretanto se foi consolidando, fez com que numa década o rácio de proteção baixasse para perto de metade (de 82,9\% para $44,8 \%)$.

Esta variação nos rácios tem sido, aliás, acompanhada por uma variação também no diferencial entre desempregados e desempregados inscritos: o número de desempregados não inscritos tem aumentado significativamente. Este dado sugere, 
por um lado, que há uma fronteira hoje ténue entre desemprego e inatividade e, por outro, que muitos desempregados não apenas deixaram de se qualificar para prestações sociais - e por isso não necessitam de cumprir o requisito formal de inscrição nos centros de emprego - como também não têm perspetivas realistas de regressar ao mercado de trabalho - ou têm alguma descrença em relação a potenciais ofertas de trabalho no âmbito de contactos com os centros de emprego.

Não obstante o exposto, em termos absolutos o número de beneficiários tem crescido ao longo dos últimos anos (de 249.527 em 2007 para 360.714 no primeiro trimestre de 2012), embora a um ritmo muito inferior ao crescimento do desemprego $-80 \%$ de crescimento do número de desempregados face a $40 \%$ de crescimento do número de beneficiários em igual período (ver anexos, figura 9).

\section{A intensidade da proteção no desemprego}

A análise da evolução dos rácios de proteção no desemprego permite-nos perceber a variação do número de desempregados a receber algum tipo de subsídio em cada momento, contudo não nos diz nada sobre a intensidade dessa proteção. Para tal, na próxima secção analisamos a alteração das regras dos subsídios de desemprego, quer em relação aos montantes, quer em relação à duração do mesmo.

No início da década de 1990, o nível de generosidade dos subsídios de desemprego resultava da reforma de 1989, que tornara o subsídio de desemprego uma prestação substitutiva dos rendimentos de trabalho, ou seja, proporcional aos últimos rendimentos auferidos, substituindo a anterior medida, que era flat-rate.

$\mathrm{Na}$ análise do período 1990-2010 verifica-se uma grande estabilidade da fórmula de cálculo e rendimentos de referência do subsídio de desemprego, alargando-se a apenas o período de referência das remunerações em 1993, de forma a reduzir as possibilidades de manipulação das remunerações de referência (ver anexos, figura 3). O plafond manteve-se estável ao longo das duas décadas, apenas variando o indexante (de $3 \times$ salário mínimo nacional - SMN para 3 × IAS em 2007). Em 1999, a duração das prestações de desemprego foi alargada para alguns escalões etários e em 2003 o PEPS estabeleceu um subsídio provisório, para o período de espera que antecede a concessão dos subsídios de desemprego, bem como uma majoração dos montantes dos subsídios - ambas medidas de natureza temporária. Em 2006, a duração dos subsídios passou a ser diferenciada de acordo com o período de registo de remunerações, bem como com a idade do requerente.

A maior alteração ao subsídio de desemprego, afetando a intensidade da proteção, ocorreu em 2012, seguindo as orientações constantes do Memorando de Entendimento - diminuição do plafond para 2,5 × IAS; redução, para cerca de metade, do período de concessão para todos os escalões; redução de $10 \%$ do montante da prestação ao fim de 180 dias de concessão do apoio. Adicionalmente, ainda no âmbito desta reforma, foi criada uma majoração de $10 \%$ do montante do subsídio para famílias monoparentais em que o parente único é titular do subsídio de desemprego ou agregados em que ambos os cônjuges, ou indivíduos em união de 
facto, são beneficiários do subsídio de desemprego - medida que já tinha sido aplicada, embora com caráter temporário, em 2010.

O subsídio social de desemprego acompanhou a evolução do subsídio de desemprego em termos de duração do período de concessão (ver anexos, figura 4). Em 1996, dada a perceção de que se tinha atingido um pico nos níveis de desemprego, e no seguimento de um acordo em sede de concertação social, a duração do subsídio social subsequente foi alargada para desempregados com idades compreendidas entre os 45 e os 54 anos. Em 1999, o montante da prestação para agregados familiares com menos de quatro elementos foi elevado para $80 \%$ do SMN e estabeleceu-se uma extensão excecional do período de concessão do subsídio para beneficiários com mais de 50 anos de idade, até ser atingida a idade de acesso à reforma antecipada.

Em 2009 e 2010, como resposta ao forte crescimento do desemprego, foi alargada em seis meses a duração dos subsídios sociais de desemprego cujo período de concessão estava previsto terminar durante estes dois anos. Por fim, em 2012, o subsídio social subsequente, que durante mais de 20 anos tivera metade da duração dos restantes subsídios de desemprego, passa a ter duração igual ao subsídio de desemprego para beneficiários com mais de 39 anos.

Embora a generosidade global das prestações de desemprego tenha permanecido relativamente estável até à última reforma de 2012, registaram-se alterações importantes no que diz respeito a uma maior ativação dos beneficiários; reforço da monitorização, combate à fraude e penalizações por incumprimento; reforço das obrigações dos beneficiários (p. ex. exigência de apresentação quinzenal nos centros de emprego, a partir de 2006); e menor margem de recusa de emprego conveniente. Estas alterações, a par da redução dos rácios de proteção, contribuíram para alguma contenção do crescimento da despesa com prestações de desemprego na segunda metade da última década, num contexto de forte crescimento da taxa de desemprego (ver anexos, figura 11).

De modo a tentar compreender de que forma os montantes dos subsídios de desemprego se relacionam com os rendimentos do trabalho, analisaremos a evolução do diferencial entre as prestações médias e as remunerações salariais médias.

Ainda que os valores médios das prestações de desemprego tenham sido invariavelmente mais baixos do que a remuneração média, até recentemente (2003), a sua variação ocorria em linha com a evolução desta. Desde então, tem-se assistido a um afastamento progressivo entre a remuneração média e o valor das prestações. Tal facto é explicável, desde logo, por um aumento da retribuição mínima mensal garantida acima do conjunto dos salários e pela desindexação dos subsídios de desemprego a este valor - o que ocorreu com a criação do IAS, em 2006. A combinação do congelamento do valor deste indexante nos últimos três anos (2009-2012) com o crescimento da retribuição mínima mensal garantida acima dos ganhos salariais médios, por si só, podem explicar o aumento deste diferencial. No entanto, pode também ser o caso de - considerando que os fluxos do emprego para o desemprego protegido se intensificaram entre os precários - termos uma formação de subsídios baseada em salários mais baixos, o que se repercute necessariamente no valor das prestações recebidas. 
Pese embora o ritmo de crescimento do desemprego em Portugal ter sido muito acelerado nos últimos anos, e bem acima da média da zona euro, o comportamento da despesa com este risco, medida em proporção do PIB, não alcançou os valores da média da UE-15. Aliás, a distância de Portugal para a esta média era em 2009 superior à registada nos anos anteriores, isto num contexto em que a despesa aumentou proporcionalmente nos dois casos. Já se compararmos o comportamento da despesa com subsídio de desemprego e a despesa com proteção social no PIB, podemos concluir que aquela tem um ritmo de crescimento muito pouco intenso, bem distante do conjunto da despesa social, mesmo num contexto de aumento de desemprego. Ainda que, no essencial dos anos, a variação da despesa com proteção no desemprego tenha sido em linha com a variação do desemprego, na segunda metade da década de 1990, e, depois, entre 2005 e 2007, assistiu-se a uma evolução da despesa em contraciclo. No primeiro caso, um ligeiro aumento da despesa num contexto de diminuição do desemprego; no segundo, uma diminuição, aliás mais acentuada, da despesa, quando os valores da taxa de desemprego subiam.

\section{Considerações finais}

O primeiro facto que resulta claro da análise das alterações na proteção no desemprego nas últimas décadas é que, apesar das mudanças recentes, assistiu-se a uma assinalável estabilidade nas regras de acesso e no montante e duração das prestações. Desde logo, as reformas corresponderam, sobretudo, a alterações paramétricas, beneficiando aqueles que já eram abrangidos pelo sistema e, no essencial, não acompanharam o ritmo de transformação do nosso mercado de trabalho. Entre os aspetos mais marcantes das alterações no SD destaca-se, por um lado, a discriminação positiva a favor de desempregados mais velhos, quer através de uma maior generosidade no apoio, quer pela facilitação do acesso à reforma antecipada (trajetória que só seria invertida em 2007, muito por força da valorização, ao nível europeu, do princípio do "envelhecimento ativo"), e, por outro, alterações significativas ao nível de procedimentos, designadamente com o reforço dos deveres dos beneficiários, que se enquadram numa tendência europeia de ativação das políticas passivas de desemprego - embora tratando-se de desenvolvimentos tardios face a muitos países europeus (ver p. ex. Clasen e Clegg, 2003; Van Gerven, 2008), tal como acontece com outras áreas de reforma no domínio da Segurança Social (Pereira, 2012). São disto exemplo o combate à fraude através do cruzamento de dados entre Segurança Social e Finanças; obrigatoriedade de comparência nos centros de emprego; redução das hipóteses de recusa de ofertas de emprego; maior flexibilidade na acumulação de benefícios com trabalho a tempo parcial.

Como sublinhámos, o nosso sistema de proteção foi desenhado para um mercado de trabalho de natureza corporativa, muito segmentado e com uma enorme dualidade entre o homem "ganha-pão" - com emprego protegido e taxas de participação elevadas - e as mulheres e os jovens - com menor proteção no emprego, salários mais baixos e menores níveis de participação -, e manteve-se estável, enquanto o mercado de trabalho evoluía a um ritmo intenso, institucionalizando-se um padrão de 
riscos muito distinto, próximo do "modelo liberal". Dois aspetos sobressaem a este nível: um crescimento muito significativo do peso dos vínculos atípicos no conjunto do emprego e um ritmo de crescimento do desemprego dos jovens muito superior ao ritmo de crescimento do desemprego total, uma evolução comum a muitos países europeus embora particularmente expressiva no caso português. A combinação destes aspetos resultou, hoje, numa descoincidência profunda entre as especificidades do desemprego e o tipo de respostas existentes. Esta tendência deverá, aliás, intensificar-se, revelando vazios crescentes na proteção, reforçando a procura de prestações de caráter mais assistencialista e, deste modo, o papel destas no regime de proteção no desemprego - desenvolvimentos que deverão merecer, em Portugal como noutros países, um debate mais aprofundado (Immervoll, 2009).

Como vimos, a diminuição dos rácios de proteção tem baixado significativamente na última década, num contexto de crescimento do desemprego. Nos próximos anos, quer por força da existência de um fluxo crescente de desempregados que não preenchem os requisitos necessários à qualificação para as prestações de desemprego (consequência de maior precariedade e maior rotação entre emprego e desemprego), quer por muitos desempregados verem os seus subsídios a terminar sem que consigam regressar ao mercado de trabalho, é bem provável que os rácios de proteção baixem a um ritmo ainda mais intenso.

Esta diminuição da proteção no desemprego acaba por ter um efeito mimético do que se está a passar no emprego, sendo ela própria segmentada. A desproteção ocorrerá com particular incidência nos segmentos à partida mais fragilizados no mercado de trabalho, e que assim acumularão fatores de exclusão. O novo regime de proteção dos trabalhadores independentes, previsto desde o Código Contributivo apresentado pelo XVIII Governo Constitucional, mas que ficou suspenso pela inexistência de uma maioria política de suporte no Parlamento, veio mais tarde a constar do Memorando de Entendimento com a troika, tendo sido aprovado recentemente. Trata-se evidentemente de um passo importante para atenuar a segmentação da proteção no desemprego. Contudo, não apenas oferece níveis de proteção duais, como terá um efeito dilatado no tempo. Em todo o caso, este conjunto de transformações recentes ocorre num contexto de residualização da proteção para muitos dos beneficiários e de prestações progressivamente menores para aqueles que eram tradicionalmente descritos como insiders.

O facto de esta diminuição de proteção ocorrer após um período em que Portugal teve rácios de desemprego protegido comparativamente elevados não pode deixar de colocar uma pressão adicional sobre o sistema de proteção social, que poderá ter também manifestações políticas.

Talvez um dos paradoxos mais surpreendentes da nossa situação radique no facto de, sendo Portugal o país com uma taxa de crescimento do desemprego mais elevada na UE-15, manter um peso da despesa com desemprego, medida em proporção do produto, comparativamente baixo. Este dado revela que não estamos perante um sistema particularmente generoso e potenciador de armadilhas de inatividade, nem por força da generosidade das prestações, nem quanto à sua duração. Ainda assim, deve referir-se que nos primeiros anos do século XXI, e perante a perceção política de que estávamos face a um pico de desemprego, assistiu-se a 
uma flexibilização das regras de acesso, de natureza temporária, mas que acabaria por se manter durante alguns anos. Mais do que de uma leitura do que seria o modelo mais adequado de proteção no desemprego, estas alterações radicaram numa leitura do comportamento conjuntural do mercado de trabalho. A este pico de generosidade e tendo em conta que o mercado de trabalho manteve um comportamento anémico, seguiu-se um período de restrição no acesso - que se foi acentuando consoante o desemprego ia aumentando e a pressão para a contenção do conjunto da despesa pública era também mais intensa. O quadro acima descrito permite traçar um padrão da evolução da proteção no desemprego em Portugal ao longo das últimas décadas. O elemento distintivo desta evolução é, a nosso ver, a mudança gradual de um modelo assente numa sobreproteção relativa dos insiders, bem como na existência de respostas para um conjunto alargado de midsiders (nomeadamente por força da criação em 1985 do SSD e, mais tarde, em 1997, do rendimento mínimo garantido, hoje RSI), para um cenário de erosão da proteção dos insiders combinada com algum, ainda que ligeiro, acréscimo na proteção dos midsiders (que decorrerá das alterações recentes, no seguimento da implementação das medidas previstas no memorando com a troika). Pese embora esta dinâmica, o sistema continua muito longe de se reconfigurar de modo a acompanhar as transformações rápidas do mercado de trabalho português - quer do ponto de vista do aumento do stock e do fluxo de desempregados, quer considerando a crescente precariedade e predomínio de relações contratuais atípicas.

Neste contexto, a par do peso crescente de desemprego de longa duração, que coloca riscos associados à sustentabilidade de níveis adequados de proteção da atual população desempregada, persiste um segmento particularmente exposto: os jovens, que apresentam uma dupla fragilidade em termos de proteção no desemprego - primeiro emprego, carreiras contributivas curtas e forte peso nos vínculos atípicos. De futuro, se bem que não se vislumbrem vazios muito significativos na proteção social (em última análise por força da existência de uma rede de mínimos sociais), é bem provável que se assista a uma trajetória de residualização da proteção no desemprego, que pode criar um stock muito significativo de midsiders, escassamente protegidos e com pouca ou nenhuma possibilidade de encontrar um emprego que se coadune com o princípio do "trabalho digno". 


\section{Anexos}

Quadro 1 Montantes referência das prestações de desemprego e rendimento social de inserção para beneficiários isolados (junho de 2012)

\begin{tabular}{ccc}
\hline Subsídio de desemprego & Subsídio social de desemprego & RSI \\
\hline $\begin{array}{c}65 \% \text { rendimento de referência } \\
\text { Máximo }=2,5 \text { x IAS (1048,06 euros) }\end{array}$ & $80 \%$ IAS (335,4euros) & $\begin{array}{c}189,52 \text { euros } \\
\text { (a partir de julho, montante passa } \\
\text { a estar indexado ao IAS) }\end{array}$ \\
\hline
\end{tabular}

Nota: IAS = indexante dos apoios sociais.

Fonte: www.seg-social.pt

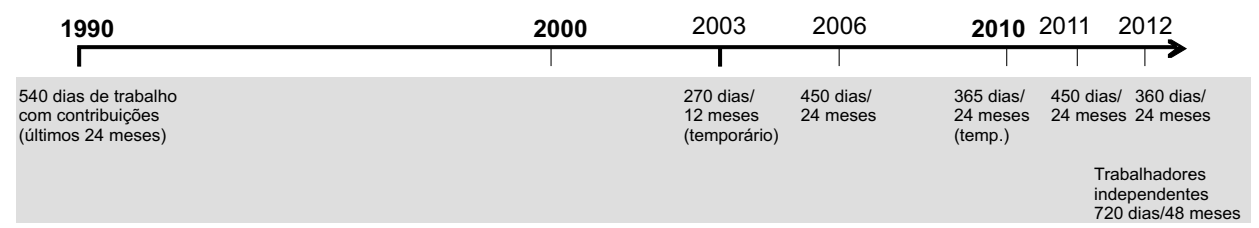

Figura 1 Evolução dos critérios de elegibilidade para acesso ao subsídio de desemprego (prazo de garantia)

\begin{tabular}{|c|c|c|c|}
\hline 1990 & 19992000 & 2009 & 10 \\
\hline $\begin{array}{l}180 \text { dias de trabalho } \\
\text { com contribuições } \\
\text { (últimos } 12 \text { meses) } \\
\text { Condição de recursos } \\
\text { Rendimento per capita } \\
<80 \% \text { SMN }\end{array}$ & $\begin{array}{l}\text { Condição de recursos } \\
\text { Alarga categorias de } \\
\text { rendimentos considerados. }\end{array}$ & $\begin{array}{l}\text { Condição de recursos } \\
\text { Aumenta limiar } \\
\text { de rendimentos } \\
\text { para } 110 \% \text { IAS. } \\
\text { (medida temporária } \\
\text { jun2009-jul2010) }\end{array}$ & $\begin{array}{l}\text { Nova lei da condição } \\
\text { de recursos } \\
\text { Alarga categorias } \\
\text { de rendimentos } \\
\text { considerados. } \\
\text { Limiar regressa } \\
\text { a } 80 \% \text { IAS }\end{array}$ \\
\hline
\end{tabular}

Figura 2 Evolução dos critérios de elegibilidade para acesso ao subsídio social de desemprego (prazo de garantia e condição de recursos)

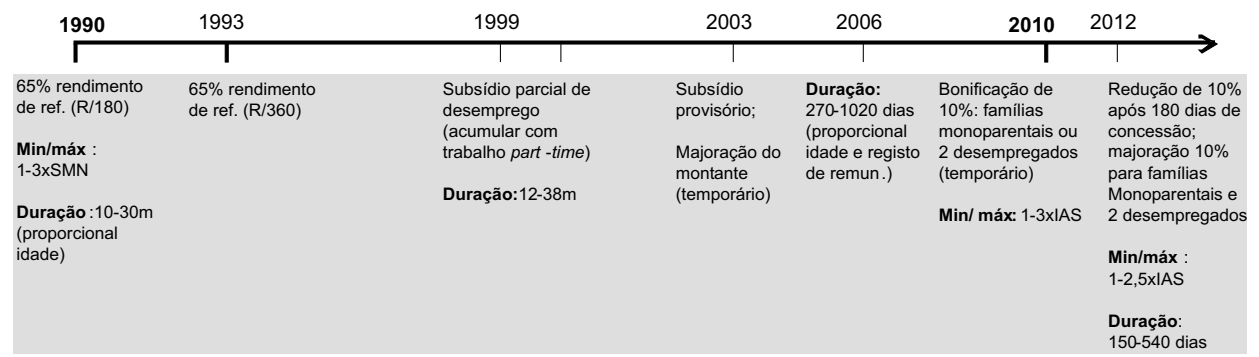

Figura 3 Evolução da generosidade do subsídio de desemprego (montante e duração) 


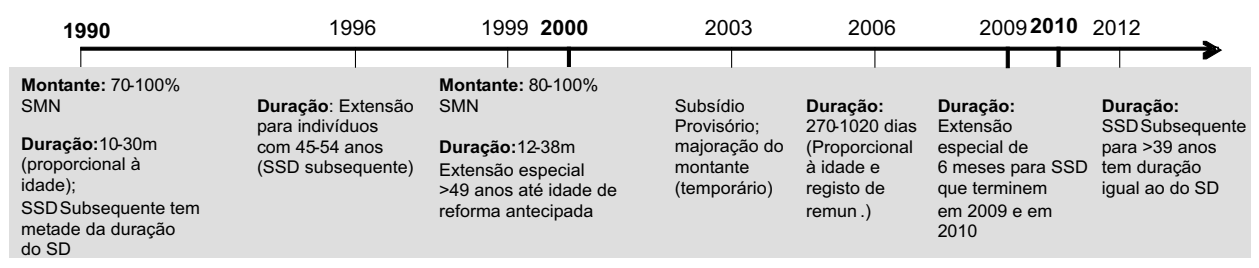

Figura 4 Evolução da generosidade do subsídio social de desemprego (montante e duração)

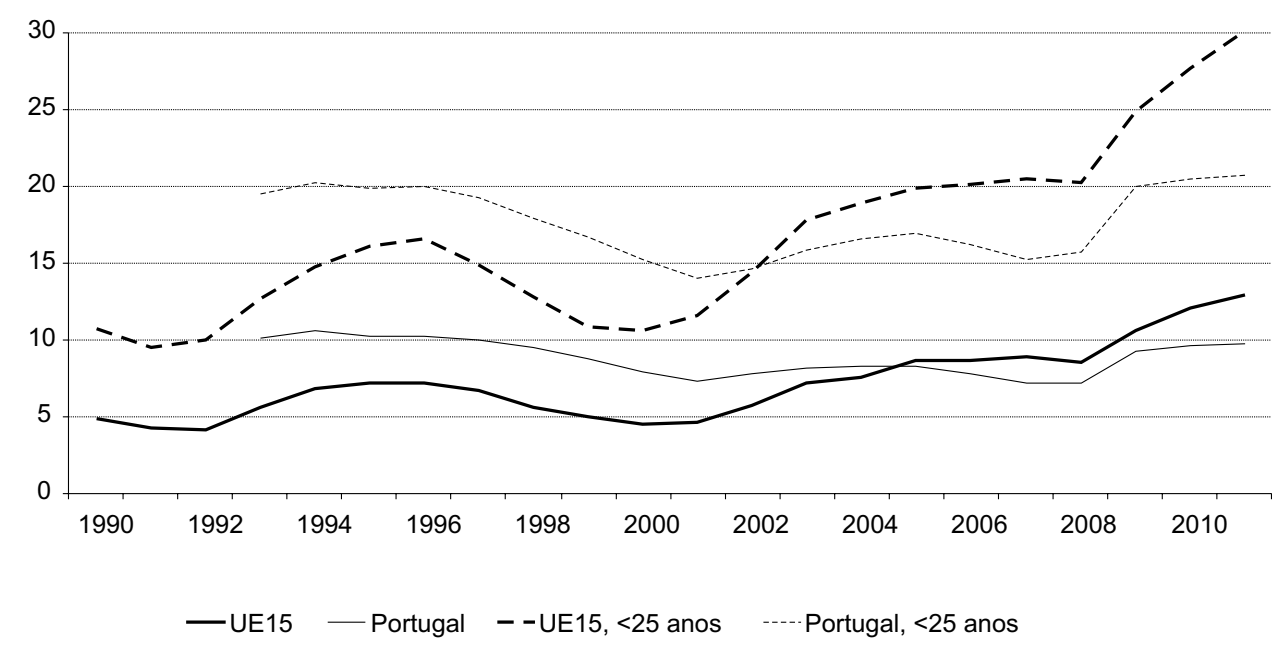

Figura 5 Taxa de desemprego (\%) - Portugal (PT), União Europeia a 15 (UE15), total e para menores de 25 anos Fonte: Eurostat.

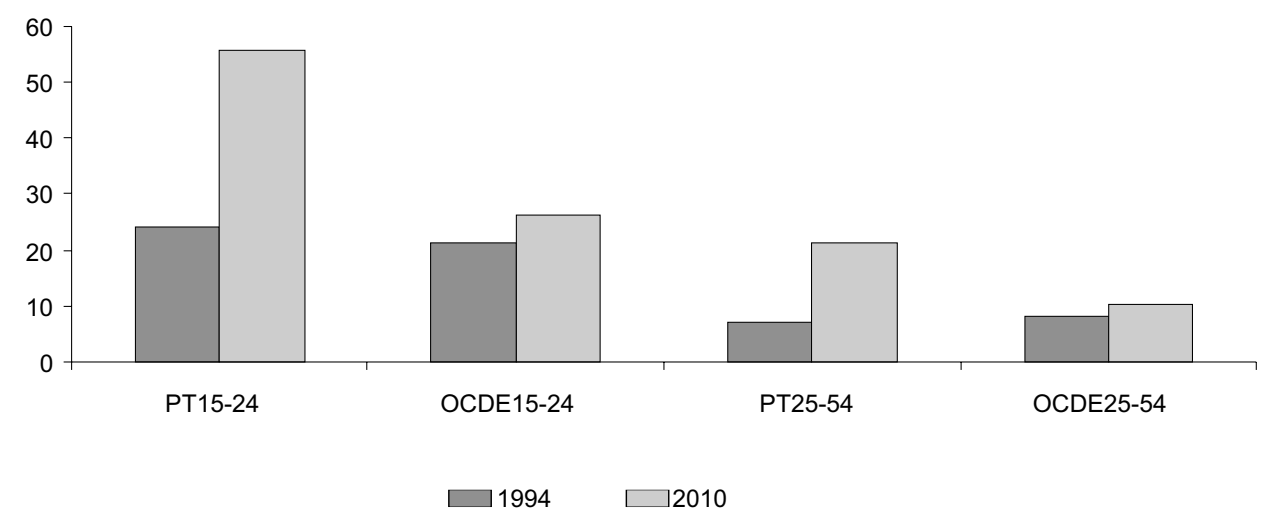

Figura 6 Emprego temporário no total do emprego (\%)

Nota: A OCDE define "emprego temporário" como aquele que compreende os trabalhadores assalariados cujo emprego tem uma data de fim preestabelecida, em oposição aos trabalhadores cujo emprego tem duração ilimitada. Fonte: OECD Online Employment Database. 


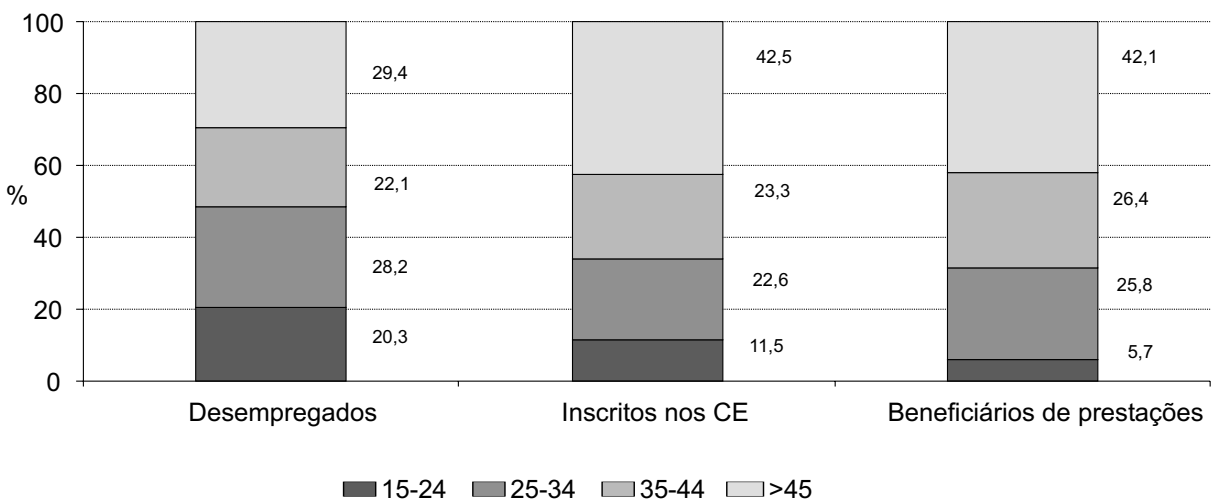

Figura 7 Desempregados, inscritos nos centros de emprego (CE) e beneficiários das prestações por escalão etário - 2011

Nota: Dados do INE para total de desempregados dizem respeito ao $4 .^{\circ}$ trimestre de 2011.

Fonte: IEFP, INE, II-MSSS.

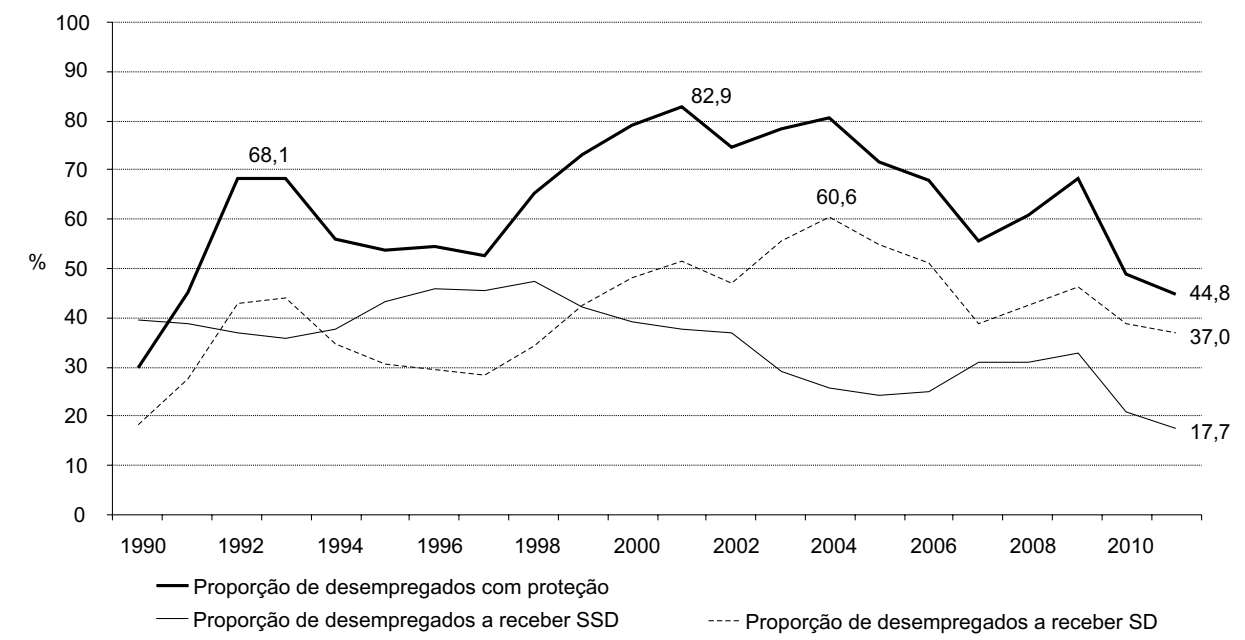

Figura 8 Desempregados beneficiários de prestações de desemprego - proporção global e por tipo de subsídio

Nota: Número total de desempregados com quebra de série nos anos de 1992, 1998 e 2011; quebra de série dos números dos beneficiários em 2004.

Fonte: Pordata. 


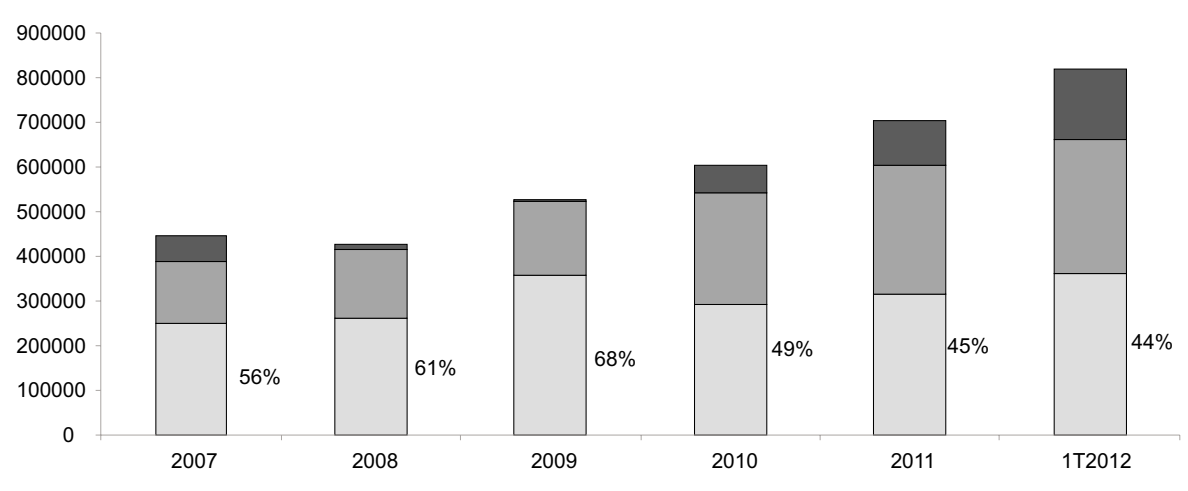

$\square$ Desempregados com proteção $\square$ Inscritos nos CE sem proteção $\square$ Desempregados não inscritos nos CE

Figura 9 Desempregados, inscritos e beneficiários de prestações de desemprego — últimos 5 anos Nota: Número total de desempregados com quebra de série em 2011.

Fonte: IEFP, INE.

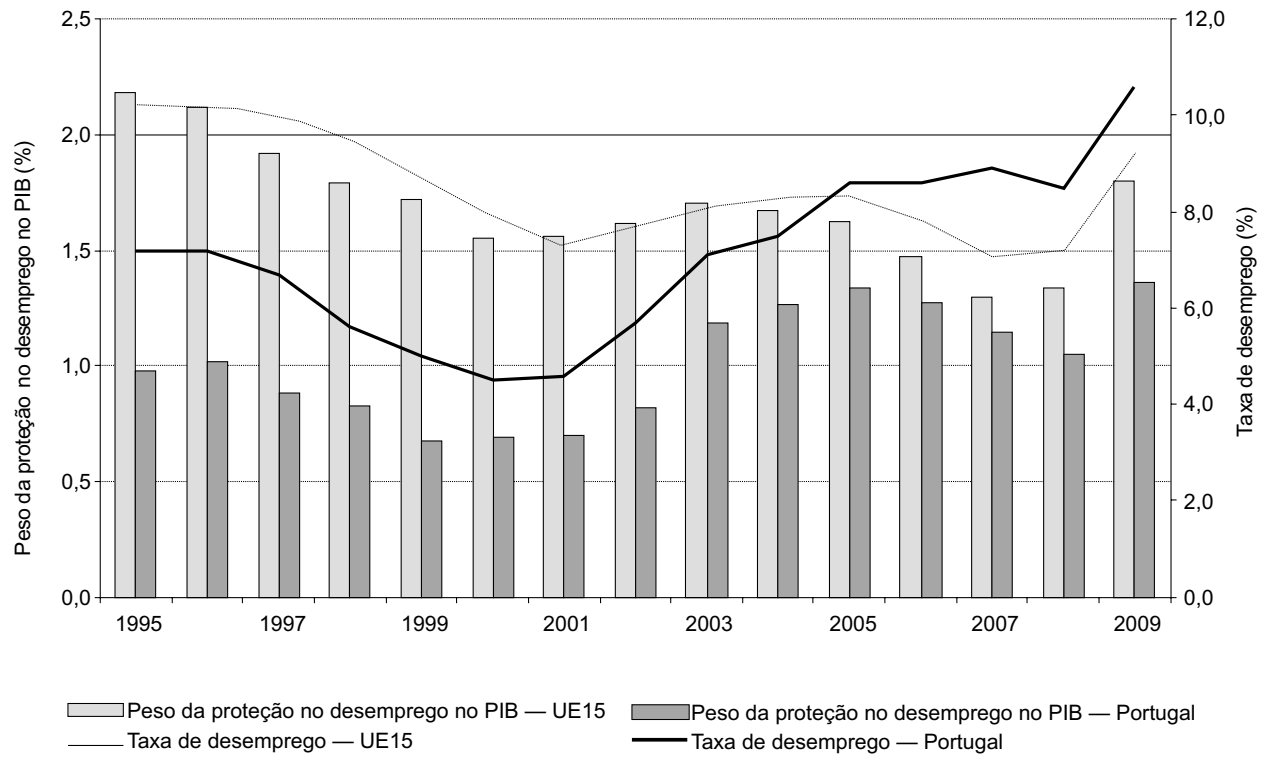

Figura 10 Despesa com proteção no desemprego (em \% PIB) e taxa de desemprego em Portugal e na Europa (UE-15)

Fonte: Eurostat. 


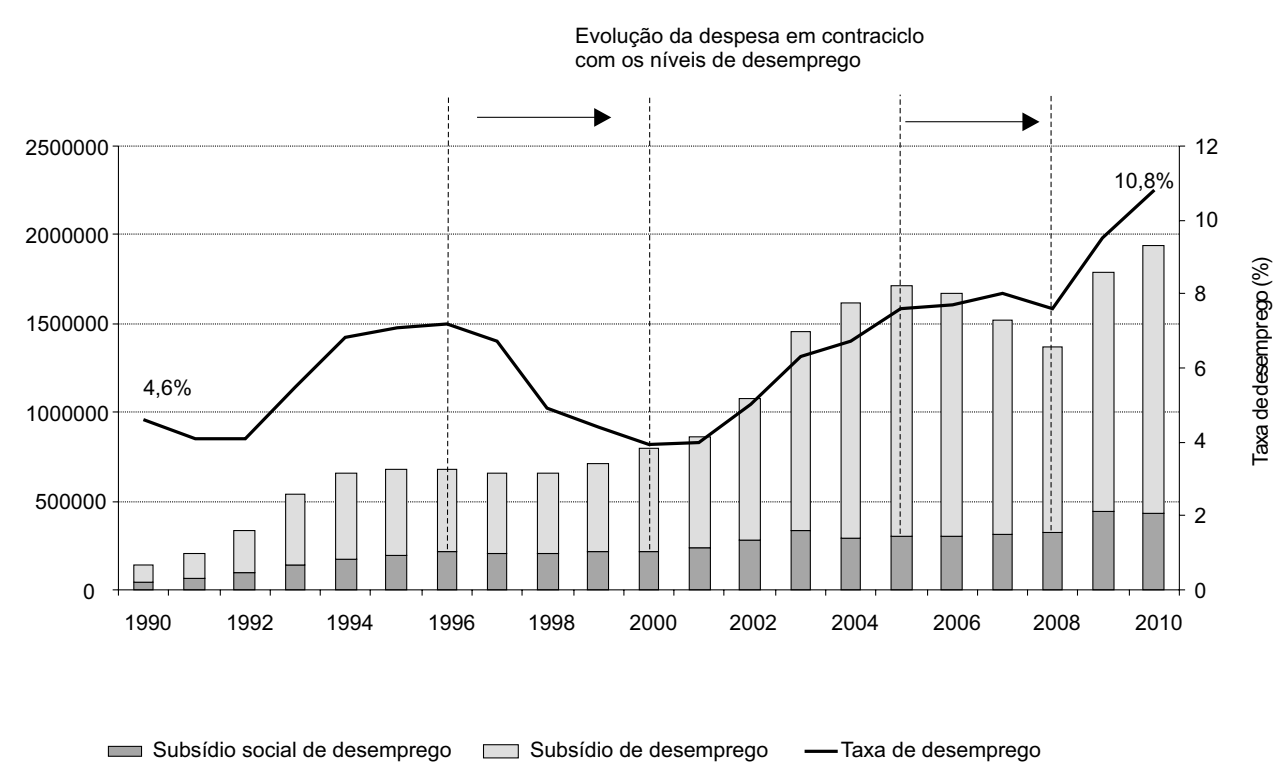

Figura 11 Despesa com prestações de desemprego (em milhares de euros) e evolução da taxa de desemprego (\%)

Nota: Taxa de desemprego com quebra de série em 1992 e 1998.

Fonte: Pordata, INE.

\section{Referências bibliográficas}

Capucha, Luís, Teresa Bomba, Rita Fernandes, e Gisela Matos (2005), “Portugal - a virtuous path towards minimum income?", em Maurizio Ferrera (org.) (2005), Welfare State Reform in Southern Europe. Fighting Poverty and Social Exclusion in Italy, Spain, Portugal and Greece, Londres, Routledge, pp. 204-265.

Centeno, Mário, e Álvaro A. Novo (2012), "Segmentação”, em Banco de Portugal, Boletim Económico. Primavera 2012, Lisboa, Banco de Portugal, pp. 7-30, http://www.bportugal. pt/pt-PT/EstudosEconomicos/Publicacoes/BoletimEconomico/BEAnteriores/Document s/bol_primavera12_p.pdf (consultado em 24/10/2012).

Clasen, Jochen, e Daniel Clegg (2003), “Unemployment protection and labour market reform in France and Great Britain in the 1990s: solidarity versus activation?", Journal of Social Policy, 32, pp. 361-381.

Dornelas, António (coord.), Antonieta Ministro, Fernando Ribeiro Lopes, José Luís Albuquerque, Maria Manuela Paixão, e Nuno Costa Santos (2011), Emprego, Contratação Colectiva de Trabalho e Protecção da Mobilidade Profissional em Portugal, Gabinete de Estratégia e Planeamento, Ministério do Trabalho e Solidariedade Social, http://pslousa.net/anexos/184_Estudo-Emprego-CCT-Mobilidade.pdf (consultado em 24/10/2012). 
Goodin, Robert E., Bruce Headey, Ruud Muffels, e Henk-Jan Dirven (1999), The Real Worlds of Welfare Capitalism, Cambridge, Cambridge University Press.

Heclo, Hugh (1974), Modern Social Politics in Britain and Sweden, Milton Keynes, ECPR Press.

Immervoll, Herwig (2009), “Minimum-income benefits in OECD countries: policy design, effectiveness and challenges", OECD Social Employment and Migration Working Papers, 100.

Kuhnle, Stein, e Anne Sander (2010), “The emergence of the western welfare state”, em Francis G. Castles, Stephan Leibfried, Jane Lewis, Herbert Obinger, e Christopher Pierson (orgs.), The Oxford Handbook of the Welfare State, Oxford, Oxford University Press, pp. 61-80.

Oliveira, Luísa, e Helena Carvalho (2010), Regulação e Mercado de Trabalho. Portugal e a Europa, Lisboa, Edições Sílabo.

Pereira, Mariana Trigo (2012), Dynamics of Reform and Adjustment of the Portuguese Social Security System. Evolution of the Sources of Finance and the Structure of Expenditure, Lisboa, ISEG-UTL, dissertação de mestrado.

Pierson, Christopher (1998), Beyond the Welfare State. The New Political Economy of Welfare, Cambridge, Polity Press.

Silva, Pedro Adão e (1998), “O RMG e a nova questão social”, Sociedade e Trabalho, 3, pp. 34-49.

Silva, Pedro Adão e (2002), “O modelo de welfare da Europa do Sul: reflexões sobre a utilidade do conceito", Sociologia, Problemas e Práticas, 38, pp. 25-59.

Silva, Pedro Adão e (2011), "The europeanisation of social policies in Portugal", Portuguese Journal of Social Science, 10 (1), pp. 3-22.

Van Gerven, Minna (2008), “Converging trends of social policy in Europe: social security benefit reform in the UK, the Netherlands and Finland", European Journal of Social Security, 10, pp. 207-225.

Venn, Danielle (2009), “Legislation, collective bargaining and enforcement: updating the OECD employment protection indicators", OECD Social, Employment and Migration Working Papers, No. 89, OECD Publishing, http://dx.doi.org/10. 1787/223334316804 (consultado em 24/10/2012).

\section{Fontes legislativas}

Decreto-Lei n.․ $79-\mathrm{A} / 89$, de 13 de março;

Decreto-Lei n. 57/96, de 22 de maio;

Decreto-Lei n. ${ }^{\circ}$ 119/99, de 11 de abril;

Decreto-Lei n. ${ }^{\circ}$ 84/2003, de 24 de abril;

Decreto-Lei n.. 220/2006, de 3 de novembro;

Decreto-Lei n.. $68 / 2009$, de 20 de março;

Decreto-Lei n.. $15 / 2010$, de 9 de mrço;

Decreto-Lei n. ${ }^{\circ}$ 70/2010, de 16 de junho;

Decreto-Lei n. ${ }^{\circ}$ 72/2010, de 18 de junho;

Decreto-Lei n. ${ }^{\circ}$ 64/2012, de 15 de março;

Decreto-Lei n.. 65/2012, de 15 de março. 
Pedro Adão e Silva. Professor auxiliar convidado, Instituto Universitário de Lisboa (ISCTE-IUL), CIES-IUL. E-mail: padaoesilva@gmail.com

Mariana Trigo Pereira. Economista, Deloitte Consultores, S.A. ${ }^{3}$ E-mail: marianatp@gmail.com

\section{Resumo/abstract/résumé/resumen}

As políticas de proteção no desemprego em Portugal

Neste artigo analisamos diacronicamente as políticas públicas de proteção do risco de desemprego em Portugal, procurando compreender quem são os desempregados protegidos e com que intensidade ocorre essa proteção. Argumentamos que pese embora Portugal, nas últimas décadas, tenha apresentado rácios de proteção no desemprego elevados, os mecanismos de proteção não só se têm revelado incapazes de se adaptar às transformações aceleradas que têm ocorrido no mercado de trabalho, deixando uma proporção crescente de desempregados desprotegidos, como se assiste a uma diminuição significativa dos valores e duração das prestações - o que não deixará de gerar "armadilhas de pobreza" entre os desempregados.

Palavras chave políticas sociais, mercado de trabalho, proteção no desemprego.

\section{Unemployment protection policies in Portugal}

In this article we analyse diachronically Portugal's pattern of unemployment protection, focusing on a description of who are the unemployed covered by social policies and the intensity of this coverage. We argue that though Portugal has presented generous ratios of protection in the last decades, mechanisms of social protection have been unable to adapt themselves to the rapid transformations that have taken place in the labour market, leaving a significant share of unemployed with no protection. Moreover, a new pattern where both the amount of subsidies and their length is diminishing might be emerging, generating "poverty traps" amongst the unemployed.

$\underline{\text { Keywords }}$ social policies, labour market, unemployment protection.

3 Este artigo é da responsabilidade da autora e não vincula a instituição a que pertence. 
Les politiques de protection des chômeurs au Portugal

Cet article présente une analyse diachronique des politiques publiques de protection contre le risque de chômage au Portugal, afin de comprendre qui sont les chômeurs protégés et l'intensité avec laquelle cette protection est appliquée. Malgré les niveaux élevés observés au Portugal au cours des dernières décennies en matière de protection des chômeurs, non seulement les mécanismes de protection se sont avérés incapables de s'adapter aux transformations accélérées du marché du travail, en laissant sans protection un nombre croissant de chômeurs, mais on assiste aussi à une baisse significative des montants et de la durée des prestations - ce qui ne manquera pas d'enfermer les chômeurs dans le "piège de la pauvreté".

Mots-clés politiques sociales, marché du travail, protection des chômeurs.

\section{Las políticas de protección durante el desempleo en Portugal}

En éste artículo analizamos diacrónicamente las políticas públicas de protección del riesgo de desempleo en Portugal, procurando comprender quienes son los desempleados protegidos y con que intensidad ocurre esa protección. Argumentamos que a pesar de que Portugal, en las últimas décadas, ha presentado niveles de protección en el desempleo elevados, los mecanismos de protección no sólo se han revelado incapaces de adaptarse a las transformaciones aceleradas que han ocurrido en el mercado de trabajo, dejando una proporción creciente de desempleados desprotegidos, así como hay una disminución significativa de los valores y duración de las prestaciones - lo que no dejará de generar "trampas de pobreza" entre los desempleados.

Palabras clave: políticas sociales, mercado de trabajo, protección en el desempleo. 